\title{
Costs of Reproduction in Breeding Female Mallards: Predation Risk during Incubation Drives Annual Mortality
}

\section{Coûts de la reproduction chez les Canards colverts femelles : le risque de prédation durant l'incubation est une facteur déterminant de la mortalité annuelle}

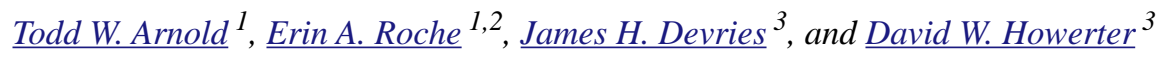

\begin{abstract}
The effort expended on reproduction may entail future costs, such as reduced survival or fecundity, and these costs can have an important influence on life-history optimization. For birds with precocial offspring, hypothesized costs of reproduction have typically emphasized nutritional and energetic investments in egg formation and incubation. We measured seasonal survival of 3856 radio-marked female Mallards (Anas platyrhynchos) from arrival on the breeding grounds through brood-rearing or cessation of breeding. There was a 2.5 -fold direct increase in mortality risk associated with incubating nests in terrestrial habitats, whereas during brood-rearing when breeding females occupy aquatic habitats, mortality risk reached seasonal lows. Mortality risk also varied with calendar date and was highest during periods when large numbers of Mallards were nesting, suggesting that prey-switching behaviors by common predators may exacerbate risks to adults in all breeding stages. Although prior investments in egg laying and incubation affected mortality risk, most relationships were not consistent with the cost of reproduction hypothesis; birds with extensive prior investments in egg production or incubation typically survived better, suggesting that variation in individual quality drove both relationships. We conclude that for breeding female Mallards, the primary cost of reproduction is a fixed cost associated with placing oneself at risk to predators while incubating nests in terrestrial habitats.
\end{abstract}

RÉSUMÉ. L'effort investi à la reproduction peut avoir une incidence sur les coûts futurs - comme un faible taux de survie ou de fertilité - et ces coûts peuvent grandement influencer l'optimisation du cycle biologique. Chez les oiseaux dont les jeunes sont nidifuges, les coûts hypothétiques de la reproduction sont surtout liés aux efforts nutritionnel et énergétique investis dans la formation des œufs et à l'incubation. Dans le cadre de cette étude, nous avons mesuré le taux de survie saisonnier de 3856 Canards colverts (Anas platyrhynchos) femelles munies d'un émetteur radio, de leur arrivée sur les aires de nidification jusqu'à ce que l'élevage des jeunes soit complété ou jusqu'à l'échec de la nidification. Le taux de mortalité était de 2,5 fois plus élevé chez les femelles qui couvaient leurs œufs en milieu terrestre, tandis qu'il a était à son plus bas niveau saisonnier au moment de l'élevage des jeunes en milieu aquatique. Le taux de mortalité a aussi varié en fonction de la date : il était à son maximum au moment où de nombreux Canards colverts nichaient, ce qui laisse croire que le changement de proies dans la diète des prédateurs communs pourrait exacerber le risque de mortalité chez les femelles à toutes les étapes de la nidification. Même si les efforts investis dans la ponte et l'incubation ont eu un effet sur le taux de mortalité, la plupart des relations n'étaient pas conformes aux prédictions de l'hypothèse des coûts de la reproduction; les femelles qui ont grandement investi dans la production d'œufs ou l'incubation ont eu un meilleur taux de survie, ce qui donne à penser que la variabilité de la qualité individuelle était responsable des deux relations. Nous concluons que, chez les femelles nicheuses de Canard colvert, le coût principal de la reproduction est un coût fixe associé au risque de prédation lié à l'incubation d'œufs en milieu terrestre.

Key Words: Anas platyrhynchos; cost of reproduction; incubation; Mallard; mortality; nesting; predation; reproductive effort; telemetry

${ }^{1}$ Department of Fisheries, Wildlife, and Conservation Biology, University of Minnesota, ${ }^{2}$ Department of Biological Sciences, University of Tulsa,

${ }^{3}$ Ducks Unlimited Canada

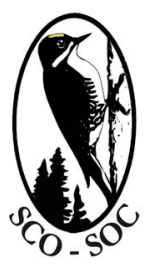

Sponsored by the Society of Canadian Ornithologists and Bird Studies Canada

Parrainée par la Société des ornithologistes du Canada et Etudes d'oiseaux Canada

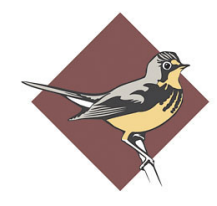




\section{INTRODUCTION}

The extent to which current reproductive effort entails a future cost by compromising an organism's ability to survive or allocate reproductive effort in the future is an integral part of a species' overall life-history strategy (Williams 1966, Stearns 1989). This trade-off is also important to population managers if attempts to increase population size by enhancing fecundity lead to concomitant reductions in survival of adult breeders (Dufour and Clark 2002). In birds, reproductive costs have most commonly been measured by reductions in survival rates of breeding adults in the year immediately following experimental increases in reproductive effort (Askenmo 1979, Nur 1984, Reid 1987). Because these costs are incurred in the future, i.e., after young have been successfully raised, they imply some sort of physiological stressor that leads to increased mortality risk (Calow 1979, Blums et al. 2005, Harshman and Zera 2006). However, pinpointing the precise cause and timing of such mortality has been hampered by methodologies such as annual mark-resighting data that measure survival only at a coarse annual scale.

Studies that have documented immediate and direct costs to breeding adults have been less common (Magnhagen 1991). During egg-laying, female birds gain mass that is not compensated for by increased muscle development, and this may impair escape flight and put gravid females at greater risk (Lee et al. 1996). Incubation and brood care are thought to place parent birds at greater predation risk (Vehrencamp 1978, Hartke et al. 2006, Low et al. 2010), but mortality of parents is much harder to document than mortality of sedentary eggs or prefledged young, and so these risks have not been well documented. Determining event-specific mortality among breeding adults generally requires techniques such as telemetry or video surveillance (Hartke et al. 2006, Reidy et al. 2009), which often precludes large samples and raises concerns that the methodologies themselves may affect mortality risks (Richardson et al. 2009, Barron et al. 2010). Nevertheless, breeding birds spend several weeks in fixed locations, i.e., nest sites, tending eggs and young, and for species that suffer high rates of nest predation this undoubtedly places them at greater risk to predators.

Nest sites and the relative safety they provide to eggs, nestlings, and attendant adults are an important component of life-history strategies in birds (Martin and Li 1992) and have also been important targets for conservation efforts (Eskowich et al. 1998, Pöysä and Pöysä 2002, Arnold et al. 2007). Mallards (Anas platyrhynchos) have highly flexible nest-site selection, but the vast majority of females nest on the ground in upland habitats, thereby exposing themselves to a large suite of terrestrial mammalian predators to which they are otherwise immune (Sargeant et al. 1993). Many of these predators are primarily nocturnal (Sargeant et al. 1993), and the combination of nesting in terrestrial habitats and incubating nests at night could place breeding females at tremendous risk. Indeed, exposure to predators during incubation is thought to be the primary determinant of male-biased sex ratios in uplandnesting waterfowl (Johnson and Sargeant 1977, Brasher et al. 2006), because males do not participate in parental care and therefore avoid such mortality. Under a scenario such as this, reproduction might entail a relatively fixed cost associated with nest attendance in risky habitat, a cost that varies little with number of offspring.

Alternatively, reproductive rates in precocial birds are widely believed to be constrained by the nutritional and energetic demands of egg formation or incubation (Ankney and Alisauskas 1991, Afton and Paulus 1992, Wiebe and Martin 2000, Lengyel et al. 2009, Sénéchal et al. 2011), leading researchers to emphasize the importance of nutrient acquisition for population management, especially during spring migration (Krapu 1981, Anteau and Afton 2009). Because of persistent renesting, individual Mallards can produce more than 30 eggs per season and spend more than 50 days incubating nests (Arnold et al. 2010), values that greatly exceed individual clutch sizes of 8-11 eggs and typical incubation periods of 23-27 days (Feldheim 1997). If these energetic investments in reproduction are the most important cost component for female ducks, then mortality risk should be primarily a function of how much individuals have invested, with persistent renesters being at greater risk of mortality.

Although there is evidence that female Mallards have higher mortality rates during the breeding season than during the nonbreeding season and that these mortality rates are higher than for males (Johnson and Sargeant 1977, Blohm et al. 1987, Brasher et al. 2006), there is little direct evidence that specific breeding activities such as egg laying, incubation, or broodrearing lead to increased mortality among breeding females. Most previous analyses have inferred correlations between mortality and breeding activity based on calendar date (Devries et al. 2003, Brasher et al. 2006). However, because of individual variation in onset of nesting along with frequent nest predation and persistent renesting (Arnold et al. 2010), individual Mallards are widely asynchronous in their breeding activities, with some individuals already engaged in broodrearing behavior before others have initiated their first nest of the season (Fig. 1). Mortality patterns could be seasonal and unrelated to breeding behavior if prey demands of predators peak concurrently with the nesting season, e.g., because predators are raising broods or litters and need more food, or other factors unrelated to reproductive effort. Therefore to clearly identify potential costs of reproduction, it is necessary to examine mortality in relation to individual breeding chronologies (Hartke et al. 2006).

We investigated costs of reproduction in female Mallards by monitoring event-specific mortality of radio-marked individuals throughout entire breeding seasons. By dividing the breeding season into separate periods of reproductive 
behavior for each individual Mallard (Pollock et al. 1989, Hartke et al. 2006), we were able to estimate daily mortality risk during each component of the breeding cycle. This allowed us to discriminate among alternate hypotheses for effects of timing per se, i.e., calendar date, current reproductive activity, e.g., incubation versus prenesting, or previous investments in egg formation or incubation. If breeding mortality is driven primarily by the chronology of predators, then calendar date should be the most important predictor of mortality risk, whereas current nesting activity should be the best predictor under the fixed-cost hypothesis, and cumulative prior investment should be the most important predictor under the traditional cost of reproduction hypothesis.

Fig. 1. Numbers of female Mallards (Anas platyrhynchos) engaged in prenesting, laying, incubation, postnesting, or brood-rearing behaviors by calendar date (1993-2000). Individuals moved through one or more categories depending on nesting activity, nesting success, and survival.

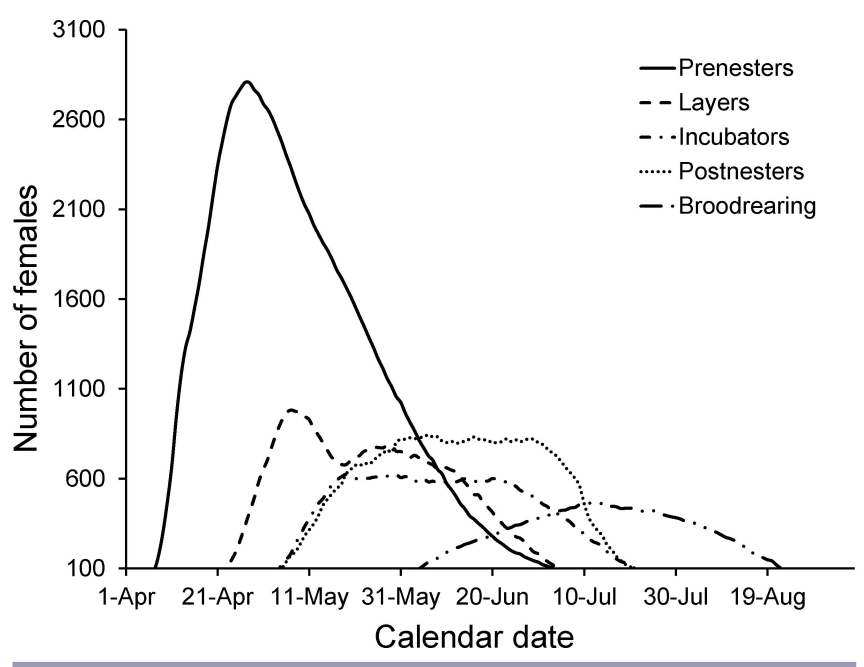

\section{METHODS}

\section{Study areas and field methods}

During 1993-2000, we collected data from 27 study sites (2-4 sites per year) in the Aspen-Parkland region of Alberta (8 sites), Saskatchewan (13 sites), and Manitoba (6 sites), Canada. Sites were typically $8.1 \times 8.1 \mathrm{~km}\left(65 \mathrm{~km}^{2}\right)$ and averaged $43 \%$ annual cropland, $6 \%$ hay land, $16 \%$ wetland, and $34 \%$ natural terrestrial vegetation, i.e., grassland, shrubland, or woodland, much of it grazed. Nine sites received little or no habitat management, nine sites received modest levels of habitat management ( $\leq 5 \%$ of the landscape), and nine sites received extensive experimental management to benefit nesting waterfowl (Arnold et al. 2007).

We used decoy traps (Sharp and Lokemoen 1987) to capture and radio-mark 3618 female Mallards (135-137 at most sites;
111 and 123 at 1993 sites). Females were captured between arrival and just prior to or concurrent with the earliest recorded nesting attempts at each site (4 April to 5 May, depending on site). On average, females were captured 24.3 days $(S D=12.9$, range $0-79$ days, $n=2783$ ) before their first observed nesting attempt, although we suspect that most of the longer values were due to failure to discover earlier nesting attempts (McPherson et al. 2003). Captured females were banded, weighed $( \pm 10 \mathrm{~g})$, radio-marked, and released back to the capture site, usually within two hours of capture. Most females (95\%) were radio-marked with 22 -g abdominally-implanted transmitters, but approximately $25 \%$ of the birds on four sites and $50 \%$ of the birds on one site were fitted with back-mounted anchor or anchor-suture transmitters (Paquette et al. 1997). Females were aged as second-year ( $\mathrm{SY}=1$-year-old; i.e., yearling) or after-second-year (ASY $=\geq 2$; i.e., adult) based on plumage characteristics (J. Devries, unpublished data); about $2 \%$ of birds could not be aged reliably and were assigned an average age of 1.6 for analysis. To bolster sample sizes during brood-rearing, an additional sample of 238 females was captured during late incubation and radio-marked with 4- or 8 -g back-mounted transmitters, similar to those used at some sites for decoy-trapped females (Bloom et al. 2012).

To identify nesting attempts and monitor female survival, we located radio-marked females one to three times daily between 0600 and 1300, from marking until mid-July using vehiclemounted, null array antenna systems (Paquette et al. 1997, Loos and Rohwer 2004). Nests of radio-marked females were monitored from a distance via telemetry until a female's absence from the nest for two consecutive location periods prompted a visit to determine nest status (Thorn et al. 2005). If the nest had failed, i.e., eggs destroyed or cold and unattended, the failure date was assumed to be the last day that telemetry indicated nest attendance. Otherwise, active nests were visited only once more at approximately 18 days of incubation (six days in 1993-1994) to determine clutch size. Because partial predation could have reduced clutch size before we measured it, we assumed that any clutches smaller than six eggs had been partially depredated $(3.6 \%$ of 1305 measured clutches; Arnold et al. 2010) and we estimated clutch size for these nests using a predictive equation (see below).

To locate females not found during daily tracking, we conducted road-based vehicle searches on and within approximately $4 \mathrm{~km}$ of study area boundaries, plus weekly searches using fixed-wing aircraft. We assumed transmitter failure when signals weakened or became erratic in the days immediately prior to signal loss. We stopped daily tracking of females if they were observed unpaired and flocked on at least two different days, or after two weeks had elapsed since the last known nest initiation on each study site. We tracked females with ducklings at least once daily until broods were $\geq 30$-days old or total brood loss occurred (Rotella and Ratti 1992). We assumed females were dead when successive radio- 
locations showed no movement or transmitters exhibited frequency changes due to temperature shifts (Devries et al. 2003), and we walked in with handheld receivers to verify mortality status.

\section{Data summarization and statistical methods}

We estimated daily mortality rates (DMR) of radio-marked females during five reproductive periods: prenesting, egg laying, incubation, postnesting, and brood-rearing (Fig. 1). We defined prenesting as the time period between capture and mortality, first nest initiation, or departure from the study site, whichever came first. Nesting periods lasted from nest discovery until hatch or nest termination and were subdivided into egg laying, i.e., first to last egg laid, and incubation, i.e., last egg laid until hatch or nest failure. For nests that were destroyed before total clutch size could be determined, we estimated clutch size as a function of initiation date, year, province, and female age $\left(R^{2}=0.496\right)$, plus a random error term to account for residual variation so that predicted clutch size had the same mean and variance as observed clutch size. We censored nesting histories of females that nested on islands $(n=97)$, in nesting structures $(n=70)$, or in deepwater vegetation ( $n=217$, defined as $>30 \mathrm{~cm}$ water depth) because we wanted all nesting females to be exposed to the same suite of terrestrial predators; however, we included data from these nesting attempts to calculate cumulative nesting effort for each female. We considered two metrics of previous nesting effort: total eggs laid and total days spent incubating, each tallied over all previous nesting attempts. On average, we discovered nests on the day the fifth egg was laid $(X=4.6, S D=2.9)$ and we discovered $94.5 \%$ of all nests before clutch completion (assuming a 9-egg clutch), but because of high nest failure rates during laying, we estimate that approximately $28 \%$ of nests (range: $9 \%-47 \%$ among sites) failed before they were discovered (McPherson et al. 2003; D. Howerter and L. Armstrong, unpublished data).

The postnesting period included the interval between nest failure and female mortality, initiation of a replacement nest, or cessation of radio-tracking, whichever came first. Finally, the brood-rearing period extended from hatch until female mortality, total brood mortality, or until we stopped monitoring broods at 30-70 days of age. Because of persistent renesting (Arnold et al. 2010), individual females could appear multiple times in the nesting and postnesting datasets, and five females that renested after experiencing total brood loss appeared twice in the brood-rearing data.

We used logistic regression to model DMR as a linear function of covariates $\left(\mathrm{X}_{1}, \mathrm{X}_{2}, \ldots \mathrm{X}_{\mathrm{k}}\right)$ using code developed for SAS NLMIXED (Rotella et al. 2004): $\operatorname{logit}(\mathrm{DMR})=\mathrm{b}_{0}+\mathrm{b}_{1} \mathrm{X}_{1}+$ $\mathrm{b}_{2} \mathrm{X}_{2}+\ldots+\mathrm{b}_{\mathrm{k}} \mathrm{X}_{\mathrm{k}}$. We used daily time intervals because this represented the typical tracking frequency. When a female was found dead several days after last being radio-tracked, we assigned time of mortality to the midpoint between detections (Paquette et al. 1997) unless available evidence, i.e., a fresh carcass, indicated otherwise. We identified 16 potential covariates that we believed might explain variation in daily mortality rates among Mallard females. Covariates specific to individual females included body mass at capture, female age (SY, ASY, or unknown), and transmitter type (implant or back-mounted). Reproductive stage, i.e., prenester, layer, incubator, postnester, or brood, was differentiated using four dummy variables, and number of days since entering each stage was denoted by using a counter variable that reset to 0 whenever birds transitioned from one reproductive stage to the next. For prenesting, laying, incubation, postnesting, and brood-rearing, this counter variable was synonymous with days since marking, eggs laid, incubation stage, days since nest failure, i.e., renest interval, and brood age, respectively. Prior nesting effort was tallied using cumulative eggs laid ( $\sum$ Eggs) and cumulative days incubated ( $\sum$ Inc) over all prior nesting attempts, excluding the current nesting attempt, which was measured using "days since" variables. Cumulative eggs laid was primarily a function of number of previous nesting attempts $\left(R^{2}=0.69\right)$ and completed clutch size explained no additional variation in this parameter, in part because so many nests were destroyed before clutch completion. Calendar date ( 1 April = 1) was a covariate that we applied across all reproductive stages. Variation in female survival due to study site and year or covariates measured at these scales (e.g., local predator communities) has been considered elsewhere (Devries et al. 2003), so for this analysis we simply accounted for such variation by considering site as a random effect in all models (Rotella et al. 2004). For relationships that were not necessarily linear on the logit scale, such as nest age, eggs laid, or calendar date, we also considered quadratic effects for each variable.

We initially considered models for all reproductive periods combined and explored sources of variation related to: (1) reproductive stage, i.e., prenesting, laying, incubation, postnesting, or brood-rearing, plus days and days ${ }^{2}$ since entering each stage, (2) calendar date (date, date ${ }^{2}$ ), or (3) previous reproductive effort, i.e., cumulative eggs, cumulative incubation, including quadratic terms. We did this by adding each suite of variables to a null model that included effects of female age, body mass (standardized to mean 0, SD 1), and transmitter type. We assessed models using Akaike's information criterion (AIC; Burnham and Anderson 2002) and analysis of deviance (ANODEV; Harris et al. 2005) and we ranked the importance of individual variables by examining test statistics, using $\alpha=0.15$ and $85 \%$ confidence intervals to maintain congruity between AIC-based model selection and parameter evaluation (Arnold 2010). If more than one variable set was explanatory, we also considered models incorporating two or more variable sets, e.g., additive and interactive combinations of reproductive stage and date.

To more fully explore factors affecting mortality risk during reproduction, we built restricted models for each of the five 
Table 1. Rankings of models of daily mortality rate in female Mallards (Anas platyrhynchos) from all breeding stages combined. Stage denotes breeding stage categories (prenesting, laying, incubating, postnesting, and brood rearing), plus linear and quadratic terms for time since entering each stage. Date includes linear and quadratic terms for calendar date, and effort includes linear and quadratic terms for number of eggs laid and number of days incubated, over all previous nesting attempts that year. Models are ranked via Akaike's information criterion $(\triangle \mathrm{AIC})$, number of parameters $(\mathrm{k})$, and percent of deviation $(-2 \log \mathrm{L})$ explained versus the simplest and fullest models (ANODEV).

\begin{tabular}{|c|c|c|c|c|}
\hline Model $^{\dagger}$ & $-2 \log \mathrm{L}$ & $\mathrm{k}$ & $\Delta \mathrm{AIC}^{\ddagger}$ & ANODEV $^{\S}$ \\
\hline Stage*Date & 9970.30 & 28 & 0.00 & $94 \%$ \\
\hline Stage*Date*Effort & 9935.58 & 52 & 13.28 & $100 \%$ \\
\hline Stage+Date+Effort & $10,003.39$ & 24 & 25.09 & $88 \%$ \\
\hline Stage+Date & $10,012.62$ & 20 & 26.32 & $86 \%$ \\
\hline Stage+Effort & $10,026.42$ & 22 & 44.12 & $84 \%$ \\
\hline Stage*Effort & $10,010.20$ & 34 & 51.90 & $87 \%$ \\
\hline Stage & $10,064.13$ & 18 & 73.83 & $77 \%$ \\
\hline Date*Effort & $10,100.41$ & 18 & 110.11 & $71 \%$ \\
\hline Date+Effort & $10,149.02$ & 10 & 142.72 & $62 \%$ \\
\hline Date & $10,204.12$ & 6 & 189.82 & $52 \%$ \\
\hline Effort & $10,344.33$ & 8 & 334.03 & $27 \%$ \\
\hline Null & $10,498.51$ & 4 & 480.21 & $0 \%$ \\
\hline
\end{tabular}

${ }^{\dagger}$ Factorial combinations denoted by *, whereas linear additive combinations of variables are denoted by + .

AIC of the top-ranked model is $10,026.30$.

${ }^{\S}$ Analysis of deviance (ANODEV) is equal to the difference in model deviance $(-2 \log L)$ between the null model and the current model, divided by the difference between the null model and the most complex model.

I A biological null model that includes effects of female age, body mass, and transmitter type.

reproductive stages. We began with full models including all explanatory variables and we sequentially reduced model complexity by eliminating one variable at a time based on minimal values of $|\beta / S E|$, as generated from the final Hessian matrix (Wolfinger 2000), except we retained weak linear effects when embedded within stronger quadratic effects. We eliminated variables up until further reductions led to increased AIC scores.

When plotting model-based estimates of daily mortality rate as a function of covariates, we set other covariates to their mean values unless this created nonsensical estimates, i.e., a female could not have already laid 20 eggs in previous nests on the first day of the nesting season. In such cases we selected biologically appropriate values of alternate covariates. For covariates with long-tailed distributions, e.g., cumulative eggs, date, we plotted estimated mortality rate versus the $90 \%$ or $95 \%$ range of the covariate, excluding the extreme $5 \%$ of observations from one or both tails so that relationships would not be driven by extreme outliers. For comparative purposes we also converted daily mortality rates into estimates of annual survivorship $\left[\mathrm{S}_{\mathrm{a}}=(1-\mathrm{DMR})^{365}\right]$; although artificial, e.g., an individual cannot incubate for 365 consecutive days, we believe these estimates provide intuitive benchmarks for comparing mortality risk among periods.

\section{RESULTS}

Our analysis included data from 3618 decoy-trapped and 238 nest-trapped females (3856 total): 3609 females contributed data on survival during the prenesting period $(94,498$ risk days), 2540 during the laying period (18,586 days), 2181 during incubation (35,266 days), 2197 during the postnesting period ( 53,852 days), and 927 during the brood-rearing period (30,631 days).

Mortality risk was affected by all three parameter sets (Table 1), but reproductive stage explained the greatest (77\%), date an intermediate amount (52\%), and prior effort the least (27\%) amount of deviance. The most parsimonious model of the combined data included interactive effects of reproductive stage and date (Appendix 1), and this model accounted for $94 \%$ of the explained deviance in the most complex model (Stage*Date*Effort), while using just $54 \%$ of the parameters (Table 1). Prenesters and layers had nearly identical patterns of seasonal mortality, and postnesters followed a similar shape, with mortality peaking near the end of May but falling off dramatically both earlier and later (Fig. 2). Mortality of incubating females also peaked in late May, but declined less dramatically, and mortality of brood-rearing females was extremely low and barely affected by calendar date (Fig. 2). 
Fig. 2. Combined effects of breeding stage and calendar date $(0=31$ March, $120=29$ July $)$ on daily mortality risk of female Mallards (Anas platyrhynchos) throughout the breeding season (top-ranked model in Table 1). Date ranges for each breeding stage omit the earliest 5\% and latest 5\% of observations (i.e., $90 \%$ ranges). Prediction intervals $(85 \%)$ are plotted for incubation and brood-rearing (lighter gray lines), but omitted from other categories to reduce overlap.

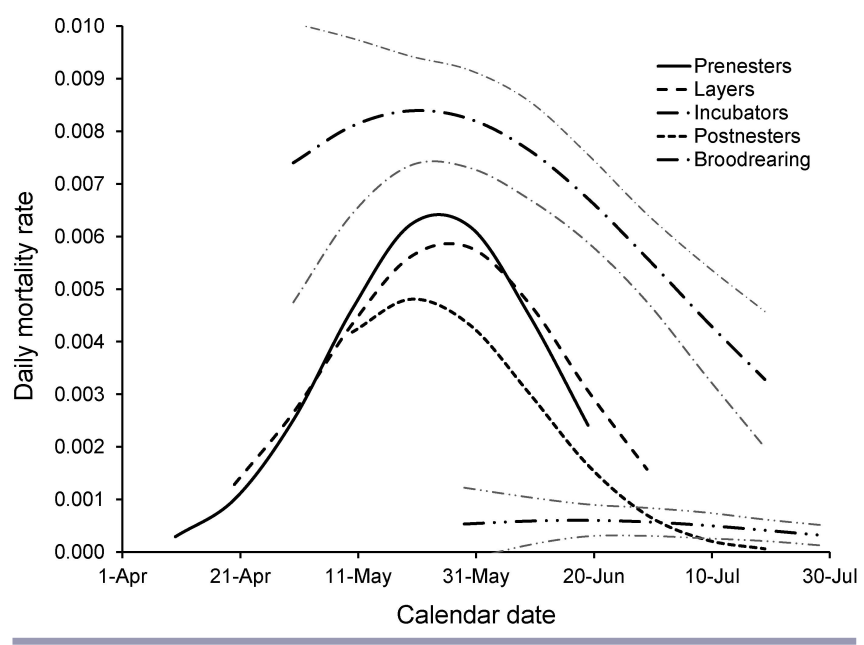

Daily mortality of prenesting and postnesting females averaged $0.00302(\mathrm{SE}=0.00024)$ and $0.00242(\mathrm{SE}=0.00033)$, respectively, which would result in annual survival of 0.331 (85\% CI: $0.292-0.376)$ and 0.413 (85\% CI: $0.346-0.492)$. Survival of prenesters was affected most strongly by calendar date and days since marking, with mortality peaking $25-45$ days after capture (Fig. 3). For each 15 day delay in radiomarking, the mortality peak occurred $\sim 5$ days later in the breeding season. Mortality of prenesting adult females was 1.2-fold higher than for yearling females $(P=0.13)$ and females marked with external transmitters had 1.6-fold greater mortality than did females marked with implant transmitters $(P=0.05)$, but mortality of prenesters was unaffected by body mass $(P=0.57)$ or study site $(P=0.73)$. Mortality of postnesting females followed a similar seasonal trajectory as for prenesting females, although peak mortality rates were lower than for prenesters (Fig. 3). Females that lost nests early in the nesting season had higher mortality and daily mortality increased for 10-15 days following nest failure, whereas females losing nests late in the nesting season had much lower mortality and mortality increased less prominently in the days immediately following nest failure (Fig. 3). Mortality was 2.4fold higher for females marked with external transmitters $(P$ $=0.03)$, but measures of previous egg laying effort $(P=0.31)$, previous incubation effort $(P=0.25)$, body mass $(P=0.74)$, and female age $(P=0.39)$ had no effect on mortality of postnesting females.
Fig. 3. Model-based estimates of daily mortality for aftersecond-year female Mallards (Anas platyrhynchos) marked with implant transmitters during prenesting (solid lines, capture dates of 1, 15, and 30 April) and postnesting (dashed lines, nest failure dates of 10 May, 30 May, and 19 June). Lines extend until $90 \%$ of the population has nested, died, or emigrated. For model equation, see Appendix 1.

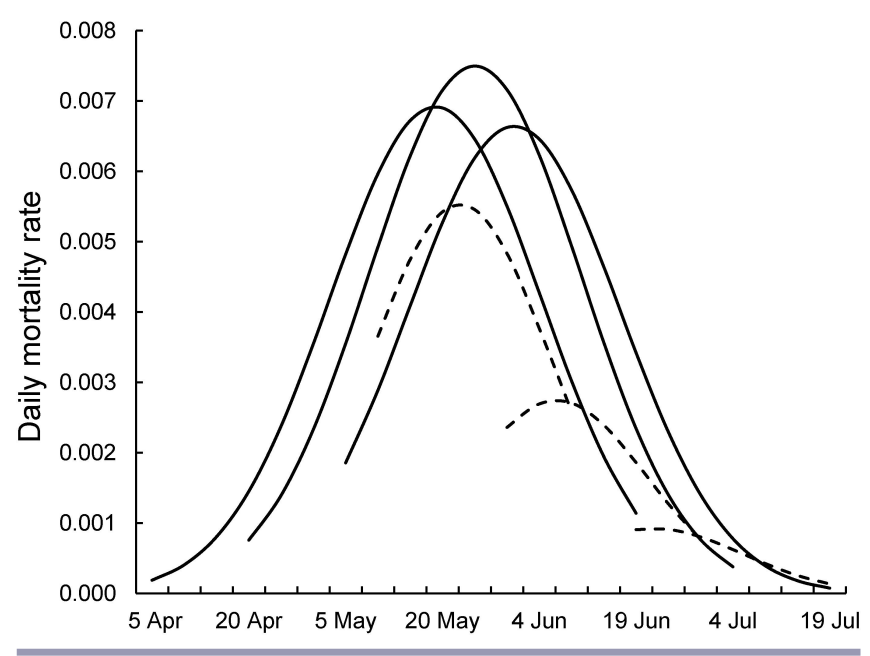

Daily mortality of layers averaged $0.00407(\mathrm{SE}=0.00070)$, which would lead to yearly survival of 0.226 if annualized (85\% CI: $0.156-0.327$ ). The best-supported model of daily mortality risk for egg laying females included quadratic effects of prior investment in egg laying and a linear effect of prior incubation (Appendix 1: Fig. A1.1), with mortality risk peaking for birds that had laid approximately 10 previous eggs but declining with previous incubation experience. There was no effect of location $(P=1.00)$, transmitter type $(P=0.98)$, female age $(P=0.80)$, body mass $(P=0.71)$, or number of eggs laid in the current clutch $(P=0.35)$ on mortality risk among layers. Daily mortality rates of incubators averaged 0.00692 ( $\mathrm{SE}=0.00067)$, which would lead to 0.079 (85\% CI: $0.056-0.113$ ) survival if annualized. Daily mortality of incubators peaked in late May, peaked at 12 days of incubation, and declined with previous investments in egg production (Fig. 4). There was no effect of body mass $(P=0.88)$, transmitter type $(P=0.77)$, female age $(P=0.59)$, or incubation of previous clutches $(P=0.18)$ on survival of incubating female Mallards.

Brood-rearing females had the lowest daily mortality risk $(0.00032 \pm 0.00014)$, which would result in 0.890 annualized survival ( $85 \%$ CI: $0.825-0.960)$. Mortality of brood-rearing females was negatively correlated with duckling age and body mass for nest-trapped females (Appendix 1: Fig. A1.2), but not for decoy-trapped females $(P=0.99)$. Mean body mass at capture for 7 nest-trapped females that died during broodrearing was $840 \mathrm{~g}$ (SE 24), versus $891 \mathrm{~g}$ (SE 4) for 231 nesttrapped females that survived $(P=0.01)$. Mortality of brood- 
rearing females was unaffected by any other covariates, including total days incubated $(P=0.95)$, total eggs laid $(P=$ $0.59)$, female age $(P=0.97)$, transmitter type $(P=0.99)$, calendar date $(P=0.43)$, and study site $(P=1.00)$.

Fig. 4. Model-based estimates of daily mortality (with $85 \%$ prediction intervals) for incubating female Mallards (Anas platyrhynchos) in relation to incubation stage, calendar date, and prior egg production. For model equations, see Appendix 1.
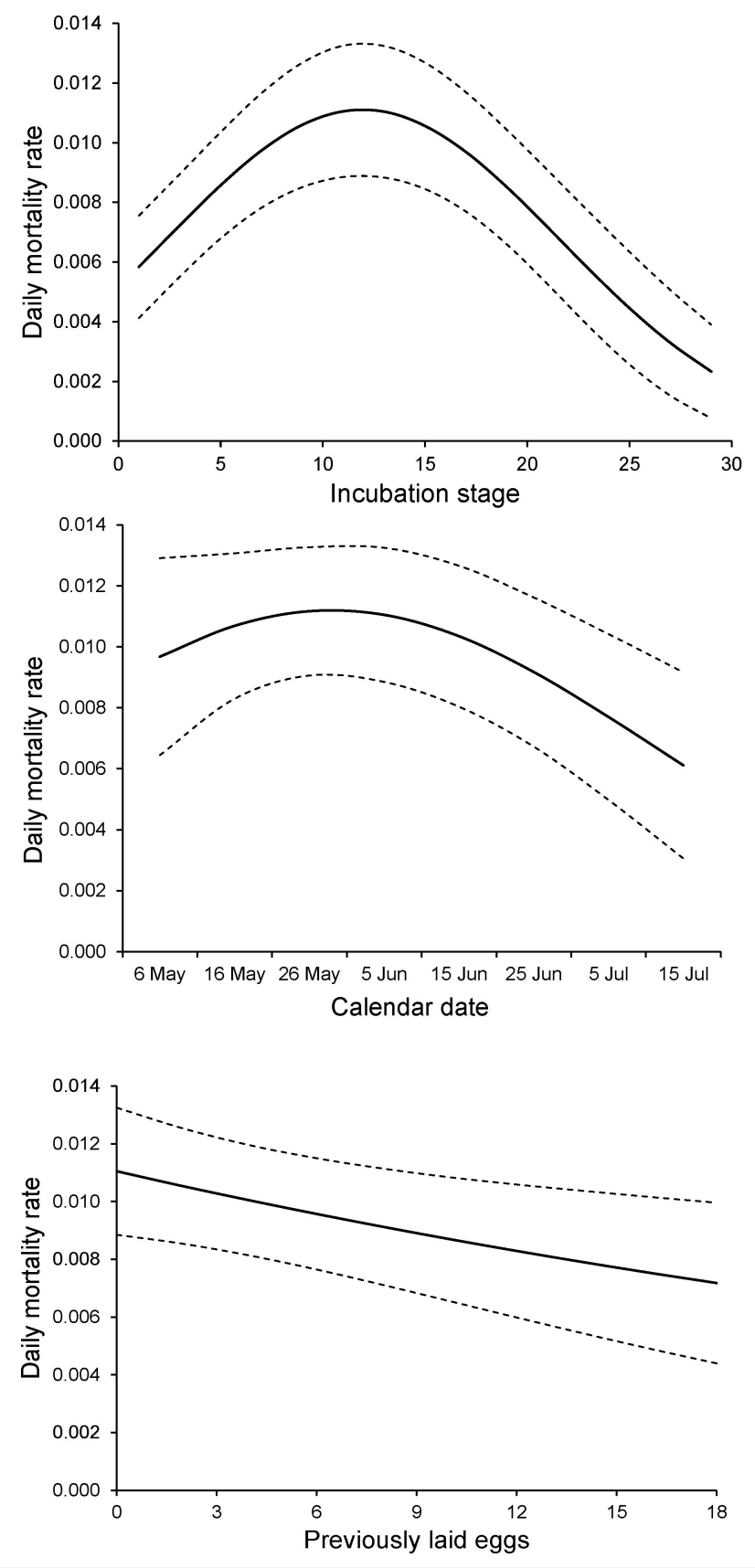

\section{DISCUSSION}

Female Mallards were subject to high levels of mortality during the breeding season; at $0.34 \%$ average mortality per day averaged over all periods, the probability of surviving the entire breeding season ( 1 Apr -31 Jul) was only $(1-0.0034)$ ${ }^{122}=0.66$. Given annual survival estimates of $\approx 0.58$ for adult female Mallards based on band-recovery data (Hoekman et al. 2002), this suggests that approximately $80 \%$ of all mortality occurs during just one third of the year during the breeding season, with virtually all of the 0.08 additional mortality outside the breeding season presumably due to hunting mortality. Studies of radio-marked female Mallards on their wintering ranges confirm that survival is higher during the nonbreeding season than during the breeding season, and that virtually all mortality during nonbreeding is caused by hunting (Dugger et al. 1994, Fleskes et al. 2007, Dooley et al. 2010; but see Bergan and Smith 1993). From a harvest management perspective, this provides little opportunity for hunting mortality of female Mallards to be compensated by reductions in natural mortality, unless predation mortality on nesting females is strongly density dependent. This preponderance of breeding season mortality among female Mallards may explain why evidence of compensatory hunting mortality has been stronger among males but absent or ambivalent among females (Burnham et al. 1984, Smith and Reynolds 1992).

Current reproductive activity had the strongest effect on mortality of female Mallards during the breeding season, with laying and incubating females experiencing 1.6- and 2.5-fold higher mortality risks than prenesters. Mortality was also affected strongly by calendar date, with mortality risk increasing during peak nesting periods, even if individual females were not nesting themselves. However, prior investments in reproduction, i.e., number of eggs laid or days incubated, had little effect on mortality, and patterns were mostly inconsistent with the cost of reproduction hypothesis. Hence, our data supported the idea of primarily fixed costs of reproduction: females engaged in laying and especially incubation behaviors in terrestrial habitats were at much higher risk of being killed by predators than were non-nesting or brood-rearing females, or concurrently monitored males (Brasher et al. 2006), and this risk had little to do with how much energy or effort had been expended in reproduction (Appendix 1: Fig. A1.3).

Although our prediction of greater mortality among nesting females was strongly supported, additional predictions about patterns of mortality among nesting females received mixed support. Female dabbling ducks gradually increase diurnal nest attendance throughout the laying period, from $<3$ hours per day at clutch initiation to $>10$ hours per day at clutch completion (Loos and Rohwer 2004). Given numerous field observations of nesting females being killed by diurnal raptors, we expected mortality risk during the laying period to exhibit an increase paralleling that of nest attendance; however, daily 
mortality risk declined nonsignificantly throughout laying. Commencement of nocturnal incubation near clutch completion resulted in an abrupt increase in mortality risk (Appendix 1: Fig. A1.3), but neither of our predictions for patterns of mortality risk during incubation were supported: we did not see a monotonic increase in mortality risk as the energetic costs of incubation increased (Krapu 1981, Sénéchal et al. 2011), nor did we see a monotonic decrease in mortality risk that might be expected under a frailty hypothesis where more vulnerable females are gradually eliminated from the risk set. Instead, mortality of nesting females peaked approximately half way through incubation (Fig. 4), a pattern we cannot readily explain. Nevertheless, given that the highest mortality of female Mallards was associated with nesting activity, providing safer nesting habitats would seem to provide twin benefits of enhanced nest survival as well as greater survival of adult females during the breeding season (Reynolds et al. 1995, Hoekman et al. 2002).

Mortality risks were at their lowest levels during broodrearing, even though brood-rearing females invest considerable time in parental activities in comparison to nonbreeding females (Afton and Paulus 1992). Most broodrearing behavior occurs in aquatic habitats where few predators are capable of capturing adult females. Mink (Neovison vison) were rare on our study sites, and even in areas where they are common, relatively few brood-rearing females succumb to predation (Amundson and Arnold 2011). Although low overall, mortality of brood-rearing females was higher during the first several days following hatch, when overland brood movements were most common (Raven et al. 2007) and duckling mortality was also highest (Bloom et al. 2012). Although mortality during brood-rearing was low, analysis of band recoveries indicated that brood-rearing was the only breeding activity that led to lower annual survival (Arnold and Howerter 2012). Presumably, lack of time to complete the wing molt and recover body condition prior to onset of fall migration and hunting seasons leads to lower survival among successfully breeding females (Leafloor and Ankney 1991).

Nonbreeding females, i.e., prenesters and postnesters, had lower mortality risk than nesters, but exhibited several temporal patterns resembling those of nesting females: their mortality risk peaked concurrently with that of nesters (Fig. 2), mortality risk of prenesters followed a similar trajectory as onset of nesting (Fig. 1), and mortality risk of postnesters peaked 5-15 days following clutch failure, similar to when females would have been initiating renests (Arnold et al. 2010). We hypothesize three potentially complementary explanations for these patterns of increased mortality risk: (1) our samples included some birds that had started nesting, but whose nests we had not yet discovered, and the elevated predation risk was due to unrecognized nesting behavior (McPherson et al. 2003), (2) these females had not yet started nesting, but they were engaged in nest prospecting behaviors, which placed them at elevated risk to terrestrial predators (McKinney et al. 1990), or (3) concurrent peaks in mortality risk may have been due to prey switching behavior by predators, and once predators had experience capturing vulnerable nesting females they were more likely to attack non-nesting females as well.

For all reproductive stages except brood-rearing, mortality risk was highest in May and June, peaking between 20 and 30 May, coincident with peak nesting activity (Fig. 1; Devries et al. 2003). Breeding densities averaged 7.5 Mallard pairs $/ \mathrm{km}^{2}$ across our 27 study areas, and including other species of upland-nesting dabbling ducks, nest densities would have been roughly three times higher (Arnold et al. 2007). Studies of important waterfowl predators have indicated pronounced switching to waterfowl prey during the nesting season (Sargeant et al. 1984, Arnold and Fritzell 1987), and studies using artificial nests have demonstrated that nest survival often varies inversely with nest density (Larivière and Messier 1998, Elmberg et al. 2009; but see Ackerman et al. 2004), suggesting that this temporal pattern might be driven by a densitydependent functional response among important predators of nesting females. Most speculation about density-dependent sources of mortality in waterfowl has focused on the nonbreeding period (Burnham et al. 1984), but if important predators of nesting females exhibit type III functional responses to increasing nest densities (Holling 1959), it could provide a mechanism to support density-dependent population regulation on the breeding grounds.

Most relationships involving prior investments in egg laying were either nonsignificant or else inconsistent with expectations of the cost of reproduction hypothesis. For example, daily mortality risk during laying initially increased with number of previously laid eggs, but it peaked at 10 eggs and declined thereafter, even though individual females produced up to 47 eggs per season. We believe this pattern was actually caused by calendar date (Fig. 2), because cumulative eggs laid was highly correlated with calendar date ( $r=0.69, n=4512$ nesting histories), and a model based on date and date ${ }^{2}$ fit the data nearly as well as the model based on cumulative eggs and eggs ${ }^{2}$ (Appendix 1: $\triangle \mathrm{AIC}=1.32$ ). During incubation, females that had laid more eggs in previous nests had lower mortality than females nesting for the first time. Similarly, prior incubation effort led to lower mortality among laying females. These observations are opposite predictions made by the cost of reproduction hypothesis and suggest at least two possible alternatives. Experience gained in prior nesting attempts may be important at minimizing predation risk in renesting attempts, or females of higher "quality" may be more likely to renest multiple times as well as more likely to survive the nesting season. Only one line of evidence supported an energetic cost of reproduction: among females captured and weighed during late incubation, light- 
weight females were more likely to die during brood-rearing (see also Hartke et al. 2006). However, this represented only seven females out of 3856. Females reach their lowest annual body mass near the end of incubation (Krapu 1981), and for at least some females, nutritional conditions at the beginning of brood-rearing may be low enough to compromise survival.

One potential criticism of these results is that we did not experimentally manipulate reproductive effort (Nur 1984); rather high investment in egg laying and incubation was a result of frequent nest loss followed by persistent renesting behavior. We believe that nest predation is largely a random process and functions as a "pseudo-experiment," but renesting propensity represents a behavioral decision, and to the extent that high quality females are more likely to renest (Arnold et al. 2010), then reproductive effort cannot be manipulated independently of female quality. Nevertheless, we believe that the ability of females to produce 2- to 4-fold more eggs than are contained in a typical clutch and not suffer higher mortality represents a critical blow to the egg-formation hypothesis (Arnold and Rohwer 1991).

More recently we have used band-recoveries from these same radio-marked birds to examine the long-term consequences of reproductive effort on vulnerability to hunting and annual survival (Arnold and Howerter 2012). Investments in nesting behavior did not affect direct recovery or survival rates, but females rearing broods had lower annual survival than did females that were unsuccessful at rearing broods, and this effect was exacerbated for late-hatched broods (Arnold and Howerter 2012), suggesting that successful reproduction may exact a reproductive cost associated with insufficient time for molting and nutrient acquisition prior to fall migration (Leafloor and Ankney 1991).

Responses to this article can be read online at: http://www.ace-eco.org/vol7/iss1/artl/responses/

\section{Acknowledgments:}

More than 200 individuals contributed to data collection and we appreciate their capable assistance. We thank L. M. CraigMoore, F. E. DeZeeuw, J. H. Giudice, P. E. Gudehus, G. G. Mack, G. H. Raven, D. W. Shaw, J. M. Warren, and especially R. B. Emery, and B. L. Joynt for supervising data collection at individual field sites. We thank Ducks Unlimited Inc., Ducks Unlimited Canada, and the U.S. Fish and Wildlife Service through the North American Wetlands Conservation Act for major financial support. Additional financial and in-kind contributions were made by the Paterson Foundation, the National Fish and Wildlife Foundation, and the Canadian Wildlife Service. We thank L. M. Armstrong and J. Fieberg for statistical advice, and H. Pöysä and an anonymous reviewer for editorial feedback.

\section{LITERATURE CITED}

Ackerman, J. T., A. L. Blackmer, and J. M. Eadie. 2004. Is predation on waterfowl nests density dependent? - Tests at three spatial scales. Oikos 107:128-140.

Afton, A. D., and S. L. Paulus. 1992. Incubation and brood care. Pages 62-108 in B. D. J. Batt, A. D. Afton, M. G. Anderson, C. D. Ankney, D. H. Johnson, J. A. Kadlec, and G. L. Krapu, editors. Ecology and management of breeding waterfowl. University of Minnesota Press, Minneapolis, Minnesota, USA.

Amundson, C. L., and T. W. Arnold. 2011. The role of predator removal, density-dependence, and environmental factors on Mallard duckling survival in North Dakota. Journal of Wildlife Management 75:1330-1339. http://dx.doi.org/10.1002/jwmg.166

Ankney, C. D, and R. T. Alisauskas. 1991. Nutrient-reserve dynamics and diet of breeding female Gadwalls. Condor 93:799-810. http://dx.doi.org/10.2307/3247714

Anteau, M. J., and A. D. Afton. 2009. Wetland use and feeding by Lesser Scaup during spring migration across the Upper Midwest, USA. Wetlands 29:704-712. http://dx.doi.org/10.16 72/08-157.1

Arnold, T. W. 2010. Uninformative parameters and model selection using Akaike's information criterion. Journal of Wildlife Management 74:1175-1178. http://dx.doi.org/10.1111/ j.1937-2817.2010.tb01236.x

Arnold, T. W., L. M. Craig-Moore, L. M. Armstrong, D. W. Howerter, J. H. Devries, B. L. Joynt, R. B. Emery, and M. G. Anderson. 2007. Waterfowl use of dense nesting cover in the Canadian Parklands. Journal of Wildlife Management 71:2542-2549. http://dx.doi.org/10.2193/2005-568

Arnold, T. W., J. H. Devries, and D. W. Howerter. 2010. Factors that affect renesting in Mallards (Anas platyrhynchos). Auk 127:212-221. http://dx.doi.org/10.1525/auk.2009.09028

Arnold, T. W., and E. K. Fritzell. 1987. Food habits of prairie mink during the waterfowl breeding season. Canadian Journal of Zoology 65:2322-2324. http://dx.doi.org/10.1139/z87-349

Arnold, T. W., and D. W. Howerter. 2012. Effects of radiotransmitters and breeding effort on harvest and survival rates of female mallards. Wildlife Society Bulletin DOI: 10.1002/wsb.134 http://dx.doi.org/10.1002/wsb.134

Arnold, T. W., and F. C. Rohwer. 1991. Do egg formation costs limit clutch size in waterfowl? A skeptical view. Condor 93:1032-1038. http://dx.doi.org/10.2307/3247744

Askenmo, C. 1979. Reproductive effort and return rate of male Pied Flycatchers. American Naturalist 114:748-753. http://dx. doi.org/10.1086/283523 
Barron, D. G, J. D. Brawn, and P. J. Weatherhead. 2010. Metaanalysis of transmitter effects on avian behavior and ecology. Methods in Ecology and Evolution 1:180-187. http://dx.doi.o rg/10.1111/j.2041-210X.2010.00013.X

Bergan J. F., and L. M. Smith. 1993. Survival rates of female Mallards wintering in the Playa Lakes Region. Journal of Wildlife Management 57:570-577. http://dx.doi.org/10.2307/3 $\underline{809284}$

Blohm, R. J., R. E. Reynolds, J. P. Bladen, J. D. Nichols, J. E. Hines, K. H. Pollock, and R. T. Eberhardt. 1987. Mallard mortality rates on key breeding and wintering areas. Transactions of the North American Wildlife and Natural Resources Conference 52:246-257.

Bloom, P. M., R. G. Clark, D. W. Howerter, and L. M. Armstrong. 2012. Landscape-level correlates of mallard duckling survival: Implications for conservation programs. Journal of Wildlife Management 76:813-823. http://dx.doi.or g/10.1002/jwmg.297

Blums, P., J. D. Nichols, J. E. Hines, M. S. Lindberg, and A. Mednis. 2005. Individual quality, survival variation and patterns of phenotypic selection on body condition and timing of nesting in birds. Oecologia 143:365-376. http://dx.doi.org/ 10.1007/s00442-004-1794-x

Brasher, M. G., T. W. Arnold, J. H. Devries, and R. M. Kaminski. 2006. Breeding-season survival of male and female Mallards in Canada's Prairie-Parklands. Journal of Wildlife Management 70:805-811. http://dx.doi.org/10.2193/0022-541X (2006)70[805:BSOMAF]2.0.CO;2

Burnham, K. P., and D. R. Anderson. 2002. Model selection and multimodel inference: a practical information-theoretic approach. Second Edition. Springer, New York, New York, USA.

Burnham, K. P., G. C. White, and D. R. Anderson. 1984. Estimating the effect of hunting on annual survival rates of adult Mallards. Journal of Wildlife Management 48:350-361. http://dx.doi.org/10.2307/3801166

Calow, P. 1979. The cost of reproduction - a physiological approach. Biological Reviews 54:23-40. http://dx.doi.org/10.1 111/j.1469-185X.1979.tb00866.X

Devries, J. H., J. J. Citta, M. S. Lindberg, D. W. Howerter, and M. G. Anderson. 2003. Breeding-season survival of Mallard females in the prairie pothole region of Canada. Journal of Wildlife Management 67:551-563. http://dx.doi.or $\mathrm{g} / 10.2307 / 3802713$

Dooley, J. L., T. A. Sanders, and P. F. Doherty, Jr. 2010. Effects of hunting season structure, weather and body condition on overwintering Mallard Anas platyrhynchos survival. Wildlife Biology 16:357-366. http://dx.doi.org/10.29 81/09-094
Dufour, K. W., and R. G. Clark. 2002. Differential survival of yearling and adult female Mallards and its relation to breeding habitat conditions. Condor 104:297-308. http://dx.doi.org/10 .1650/0010-5422(2002)104[0297:DSOYAA]2.0.CO;2

Dugger, B. D., K. J. Reinecke, and L. H. Fredrickson. 1994. Late winter survival of female Mallards in Arkansas. Journal of Wildlife Management 58:94-99. http://dx.doi.org/10.2307/3 $\underline{809554}$

Elmberg, J., K. Folkesson, M. Guillemain, and G. Gunnarsson. 2009. Putting density dependence in perspective: nest density, nesting phenology, and biome, all matter to survival of simulated Mallard Anas platyrhynchos nests. Journal of Avian Biology 40:317-326. http://dx.doi.org/10.1111/j.1600-048X.2 $\underline{008.04543 . x}$

Eskowich, K., D. McKinnon, G. Brewster, and K. Belcher. 1998. Preference and use of nest baskets and nest tunnels by Mallards in the parkland of Saskatchewan. Wildlife Society Bulletin 26:881-885.

Feldheim, C. L. 1997. The length of incubation in relation to nest initiation date and clutch size in dabbling ducks. Condor 99:997-1001. http://dx.doi.org/10.2307/1370155

Fleskes, J. P., J. L. Yee, G. S. Yarris, M. R. Miller, and M. L. Casazza. 2007. Pintail and Mallard survival in California relative to habitat, abundance, and hunting. Journal of Wildlife Management 71:2238-2248. http://dx.doi.org/10.2193/2005-634

Harris, M. P., T. Anker-Nilssen, R. H. McCleery, K. E. Erikstad, D. N. Shaw, and V. Grosbois. 2005. Effect of wintering area and climate on the survival of adult Atlantic Puffins Fratercula arctica in the eastern Atlantic. Marine Ecology Progress Series 297:283-296. http://dx.doi.org/10.33 54/meps 297283

Harshman, L. G., and A. J. Zera. 2006. The cost of reproduction: the devil in the details. Trends in Ecology \& Evolution 22:80-86. http://dx.doi.org/10.1016/j.tree.2006.10.008

Hartke, K. M., J. B. Grand, G. R. Hepp, and T. H. Folk. 2006. Sources of variation in survival of breeding female Wood Ducks. Condor 108:201-210. http://dx.doi.org/10.1650/00105422(2006)108[0201:SOVISO]2.0.CO;2

Hoekman, S. T., L. S. Mills, D. W. Howerter, J. H. Devries, and I. J. Ball. 2002. Sensitivity analyses of the life cycle of midcontinent Mallards. Journal of Wildlife Management 66:883-900. http://dx.doi.org/10.2307/3803153

Holling, C. S. 1959. The components of predation as revealed by a study of small-mammal predation of the European pine sawfly. Canadian Entomologist 91:293-320. http://dx.doi.org /10.4039/Ent91293-5 
Johnson, D. H., and A. B. Sargeant. 1977. Impact of red fox predation on the sex ratio of Mallards. U. S. Fish and Wildlife Service Wildlife Research Report 6, Northern Prairie Wildlife Research Center, Jamestown, North Dakota, USA.

Krapu, G. L. 1981. The role of nutrient reserves in Mallard reproduction. Auk 98:29-38.

Larivière, S., and F. Messier. 1998. Effect of density and nearest neighbours on simulated waterfowl nests: can predators recognize high-density nesting patches? Oikos 83:12-20. http://dx.doi.org/10.2307/3546541

Leafloor, J. O., and C. D. Ankney. 1991. Factors affecting wing molt chronology of female Mallards. Canadian Journal of Zoology 69:924-928. http://dx.doi.org/10.1139/z91-137

Lee, S. J., M. S. Witter, I. C. Cuthill, and A. R. Goldsmith. 1996. Reduction in escape performance as a cost of reproduction in Gravid Starlings, Sturnus vulgaris. Proceedings of the Royal Society of London B 263:619-623. http://dx.doi.org/10.1098/rspb.1996.0093

Lengyel, S., B. Kiss, and C. R. Tracy. 2009. Clutch size determination in shorebirds: revisiting incubation limitation in the Pied Avocet (Recurvirostra avosetta). Journal of Animal Ecology 78:396-405. http://dx.doi.org/10.1111/j.1365-2656.2 008.01486.x

Loos, E. R., and F. C. Rohwer. 2004. Laying-stage nest attendance and onset of incubation in prairie nesting ducks. Auk 121:587-599. http://dx.doi.org/10.1642/0004-8038(2004) 121[0587:LNAAOO]2.0.CO;2

Low, M., D. Arlt, S. Eggers, and T. Pärt. 2010. Habitat-specific differences in adult survival rates and its links to parental workload and on-nest predation. Journal of Animal Ecology 79:214-224. http://dx.doi.org/10.1111/j.1365-2656.2009.01595. $\underline{\mathrm{x}}$

McKinney, F., D. Buitron, and S. R. Derrickson. 1990. Persistent quacking in dabbling ducks: a predator-luring signal. Wildfowl 41:92-98.

McPherson, R. J., T. W. Arnold, L. M. Armstrong, and C. J. Schwarz. 2003. Estimating the nest-success rate and the number of nests initiated by radiomarked Mallards. Journal of Wildlife Management 67:843-851. http://dx.doi.org/10.230 $\underline{7 / 3802691}$

Magnhagen, C. 1991. Predation risk as a cost of reproduction. Trends in Ecology \& Evolution 6:183-186. http://dx.doi.org/1 $\underline{0.1016 / 0169-5347(91) 90210-\mathrm{O}}$

Martin, T. E., and P. Li. 1992. Life history traits of open- vs. cavity-nesting birds. Ecology 73:579-592. http://dx.doi.org/1 $\underline{0.2307 / 1940764}$

Nur, N. 1984. The consequences of brood size for breeding Blue Tits I. Adult survival, weight change and the cost of reproduction. Journal of Animal Ecology 53:479-496. http://d x.doi.org/10.2307/4529

Paquette, G. A., J. H. Devries, R. B. Emery, D. W. Howerter, B. L. Joynt, and T. P. Sankowski. 1997. Effects of transmitters on reproduction and survival of wild Mallards. Journal of Wildlife Management 61:953-961. http://dx.doi.org/10.2307/3 $\underline{802205}$

Pollock, K. H., S. R. Winterstein, and M. J. Conroy. 1989. Estimation and analysis of survival distributions for radiotagged animals. Biometrics 45:99-109. http://dx.doi.org/10.23 $\underline{07 / 2532037}$

Pöysä, H., and S. Pöysä. 2002. Nest-site limitation and density dependence of reproductive output in the Common Goldeneye Bucephala clangula: implications for the management of cavity-nesting birds. Journal of Animal Ecology 39:502-510. http://dx.doi.org/10.1046/j.1365-2664.2002.00726.x

Raven, G. H. , T. W. Arnold, D. W. Howerter, and L. M. Armstrong. 2007. Mallard brood movements in the Canadian Prairie Parklands. Prairie Naturalist 39:1-13.

Reid, W. V. 1987. The cost of reproduction in the Glaucouswinged Gull. Oecologia 74:458-467. http://dx.doi.org/10.1007/ BF00378945

Reidy, J. L., M. M. Stake, and F. R. Thompson III. 2009. Nocturnal predation of females on nests: an important source of mortality for Golden-cheeked Warblers? Wilson Journal of Ornithology 121:416-421. http://dx.doi.org/10.1676/08-076.1

Reynolds, R. E., R. J. Blohm, J. D. Nichols, and J. E. Hines. 1995. Spring-summer survival rates of yearling versus adult Mallard females. Journal of Wildlife Management 59:691-696. http://dx.doi.org/10.2307/3801945

Richardson, T. W., T. Gardali, and S. H. Jenkins. 2009. Review and meta-analysis of camera effects on avian nest success. Journal of Wildlife Management 73:287-293. http://dx.doi.or $\mathrm{g} / 10.2193 / 2007-566$

Rotella, J. J., S. J. Dinsmore, and T. L. Shaffer. 2004. Modeling nest-survival data: a comparison of recently developed methods that can be implemented in MARK and SAS. Animal Biodiversity and Conservation 27:187-205.

Rotella, J. J., and J. T. Ratti. 1992. Mallard brood survival and wetland habitat conditions in southwestern Manitoba. Journal of Wildlife Management 56:499-507. http://dx.doi.org/10.230 7/3808865

Sargeant, A. B., S. H. Allen, and R. T. Eberhardt. 1984. Red fox predation on breeding ducks in the midcontinent North America. Wildlife Monographs 89.

Sargeant, A. B., R. J. Greenwood, M. A. Sovada, and T. L. Schaffer. 1993. Distribution and abundance of predators that 
affect duck production: Prairie Pothole Region. U.S. Fish and Wildlife Service Resource Publication 194, Northern Prairie Wildlife Research Center, Jamestown, North Dakota, USA.

Sénéchal, É., J. Bêty, and H. G. Gilchrist. 2011. Interactions between lay date, clutch size, and postlaying energetic needs in a capital breeder. Behavioral Ecology 22:162-168. http://d x.doi.org/10.1093/beheco/arq189

Sharp, D. E., and J. T. Lokemoen. 1987. A decoy trap for breeding-season Mallards in North Dakota. Journal of Wildlife Management 51:711-715. http://dx.doi.org/10.2307/3801731

Smith, G. W., and R. E. Reynolds. 1992. Hunting and Mallard survival, 1979-88. Journal of Wildlife Management 56:306-316. http://dx.doi.org/10.2307/3808827

Stearns, S. C. 1989. Trade-offs in life-history evolution. Functional Ecology 3:259-268. http://dx.doi.org/10.2307/238 $\underline{9364}$

Thorn, T. D., R. B. Emery, D. W. Howerter, J. H. Devries, and B. L. Joynt. 2005. Use of radio-telemetry to test for investigator effects on nesting Mallards (Anas platyrhynchos). Canadian Field Naturalist 119:1-5.

Vehrencamp, S. L. 1978. The adaptive significance of communal nesting in Groove-billed Anis (Crotophaga sulcirostris). Behavioral Ecology and Sociobiology 4:1-33. http://dx.doi.org/10.1007/BF00302558

Wiebe, K. L., and K. Martin. 2000. The use of incubation behavior to adjust avian reproductive costs after egg laying. Behavioral Ecology and Sociobiology 48:463-470. http://dx.d oi.org/10.1007/s002650000259

Williams, G. C. 1966. Natural selection, the costs of reproduction, and a refinement of Lack's principle. American Naturalist 100:687-690. http://dx.doi.org/10.1086/282461

Wolfinger, R. D. 2000. Fitting nonlinear mixed models with the new NLMIXED procedure. SAS Institute Inc., Cary, North Carolina, USA. 
Appendix 1. Top supported models $(\triangle \mathrm{AIC}=0)$ or competitive non-nested models $(\triangle \mathrm{AIC}<2)$ of daily survival rate (DSR) for adult female mallards throughout the breeding season. Standard errors of regression coefficients are provided in square brackets, and random effects, if supported, are presented with the intercept term $( \pm \varepsilon)$. These models were used to create figures of daily mortality rates (1 - DSR) throughout the manuscript. Figures of significant relationships not illustrated in the manuscript are also presented. Date is Julian date - 90 (i.e. $1=1$ Apr). Layer, Incubator, Postnester, and Brood are dummy variables ( 1 if bird is in category, 0 if not). DaysSinceMarking, EggsLaid, IncStage, RenestInterval, and BroodAge represent days since entering each of the 5 reproductive categories. $\sum$ Eggs and $\sum$ Inc are numbers of eggs laid or days incubated in prior nesting attempts, respectively. FAge is female age $(2,1$, or 1.6 if unknown), XMT is a dummy variable denoting an external transmitter, Mass is standardized body mass from decoy trapping, and Mass 2 is standardized body mass for females first captured during late incubation.

\section{Combined reproductive periods (Fig. 2):}

$$
\begin{aligned}
& \operatorname{logit}(\mathrm{DSR})=9 \cdot 13[0 \cdot 54]-0 \cdot 104[0 \cdot 033] * \text { Date }+0 \cdot 00095[0 \cdot 000365] * \text { Date }^{2}- \\
& 0 \cdot 782[1 \cdot 565] \text { * Layer }-3 \cdot 211[0 \cdot 966] \text { * Incubator }-1 \cdot 143[1 \cdot 567] * \text { Postnester }+ \\
& \text { 0.0753[0.0058] * Brood - 0.0627[0.0236] * DaysSinceMarking + } \\
& \text { 0.000863[0.000395] * DaysSinceMarking }{ }^{2}+0 \cdot 134 \text { [0.209] * EggsLaid - } \\
& 0 \cdot 0103[0 \cdot 0180] * \text { EggsLaid }{ }^{2}-0 \cdot 127[0 \cdot 035] * \text { IncStage }+0 \cdot 00524[0 \cdot 00146] * \\
& \text { IncStage }^{2}-0 \cdot 0729[0 \cdot 0331] * \text { RenestInterval }+0 \cdot 00181[0 \cdot 00105] \text { * } \\
& \text { RenestInterval }^{2}-0 \cdot 0613[0 \cdot 1257] * \text { BroodAge }+0 \cdot 00534[0 \cdot 00475] * \text { BroodAge }^{2}- \\
& 0 \cdot 0942[0 \cdot 0800] * \text { FAge }-0 \cdot 433[0 \cdot 136] * \text { XMT }+0 \cdot 0106[0 \cdot 0384] * \text { Mass - } \\
& 0 \cdot 0179[0 \cdot 0601] * \text { Date }^{*} \text { Layer }+0 \cdot 000140[0 \cdot 000570] * \text { Date }^{2} * \text { Layer }+ \\
& 0 \cdot 0828[0 \cdot 0408] * \text { Date * Incubator }-0 \cdot 000720[0 \cdot 000403] * \text { Date }^{2} * \text { Incubator }+ \\
& \text { 0.00981[0.0576] * Date * Postnester }+0 \cdot 000086[0 \cdot 000514] * \text { Date }^{2} * \text { Postnester }+ \\
& 0 \cdot 0700[0 \cdot 1263] * \text { Date }^{*} \text { Brood }-0 \cdot 000800[0 \cdot 000720] * \text { Date }^{2} * \text { Brood }
\end{aligned}
$$

Prenesting period (Fig. 3): 
$\operatorname{logit}(\mathrm{DSR})=9 \cdot 60[0 \cdot 574]-0 \cdot 1207[0 \cdot 0335] *$ Date $+0 \cdot 00112[0 \cdot 00037] *$ Date $^{2}-$

$0 \cdot 0565[0 \cdot 0237] *$ DaysSinceMarking $+0 \cdot 000757[0 \cdot 000395] *$

DaysSinceMarking ${ }^{2}-0 \cdot 491[0 \cdot 196] *$ XMT $-0 \cdot 206[0 \cdot 119] *$ FAge

Laying period (graphed below):

$\operatorname{logit}(\mathrm{DSR})=5 \cdot 49[0 \cdot 15]-0 \cdot 117[0 \cdot 052] * \sum \mathbf{E g g s}+0 \cdot 00605[0 \cdot 00325] * \sum \mathbf{E g g s}^{2}+$

$0 \cdot 0683[0 \cdot 0397] * \sum \mathbf{I n c} ;-2 \log$ Likelihood $=1067 \cdot 16, \mathrm{AIC}=1075 \cdot 16$

$\operatorname{logit}(\mathrm{DSR})=7 \cdot 27[1 \cdot 28]-0 \cdot 0767[0 \cdot 0465] *$ Date $+0 \cdot 000710[0 \cdot 000403] *$ Date $^{2} ;-2$ log

Likelihood $=1070 \cdot 48, \mathrm{AIC}=1076 \cdot 48$ (graph is nearly identical to Fig. 2).

Incubation period (Fig. 4):

$\operatorname{logit}(\mathrm{DSR})=6 \cdot 12[0 \cdot 84] \pm 0 \cdot 152[0 \cdot 087] * \operatorname{Site}(\varepsilon)-0 \cdot 0289[0 \cdot 0249] *$ Date +

$0 \cdot 000244[0 \cdot 000179] *$ Date $^{2}-0 \cdot 129[0 \cdot 036] *$ IncStage $+0 \cdot 00541[0 \cdot 00147] *$

IncStage $2+0 \cdot 0251[0 \cdot 0152] * \sum$ Eggs

Postnesting period (Fig. 3):

$\operatorname{logit}(\mathrm{DSR})=6 \cdot 36[1 \cdot 37] \pm 0 \cdot 258[0 \cdot 140] *$ Site $(\varepsilon)-0 \cdot 0428[0 \cdot 0437] *$ Date +

$0 \cdot 000647[0 \cdot 000331] *$ Date $^{2}-0 \cdot 0780[0 \cdot 0332] *$ RenestInterval +

$0 \cdot 00191[0 \cdot 00105] *$ RenestInterval $^{2}-0 \cdot 832[0 \cdot 370] *$ XMT

Brood-rearing period (graphed below):

$\operatorname{logit}(\mathrm{DSR})=6 \cdot 69[0 \cdot 44]+0 \cdot 0774[0 \cdot 0401] *$ BroodAge $+1 \cdot 405[0 \cdot 369] *$ Mass2 
Fig. A1.1 Model-based estimates of daily mortality (with $85 \%$ prediction intervals) for female mallards during the laying period in relation to previous investment in reproduction (top; solid lines $=$ eggs laid in previous nests, dashed lines $=$ days incubated in previous nests).

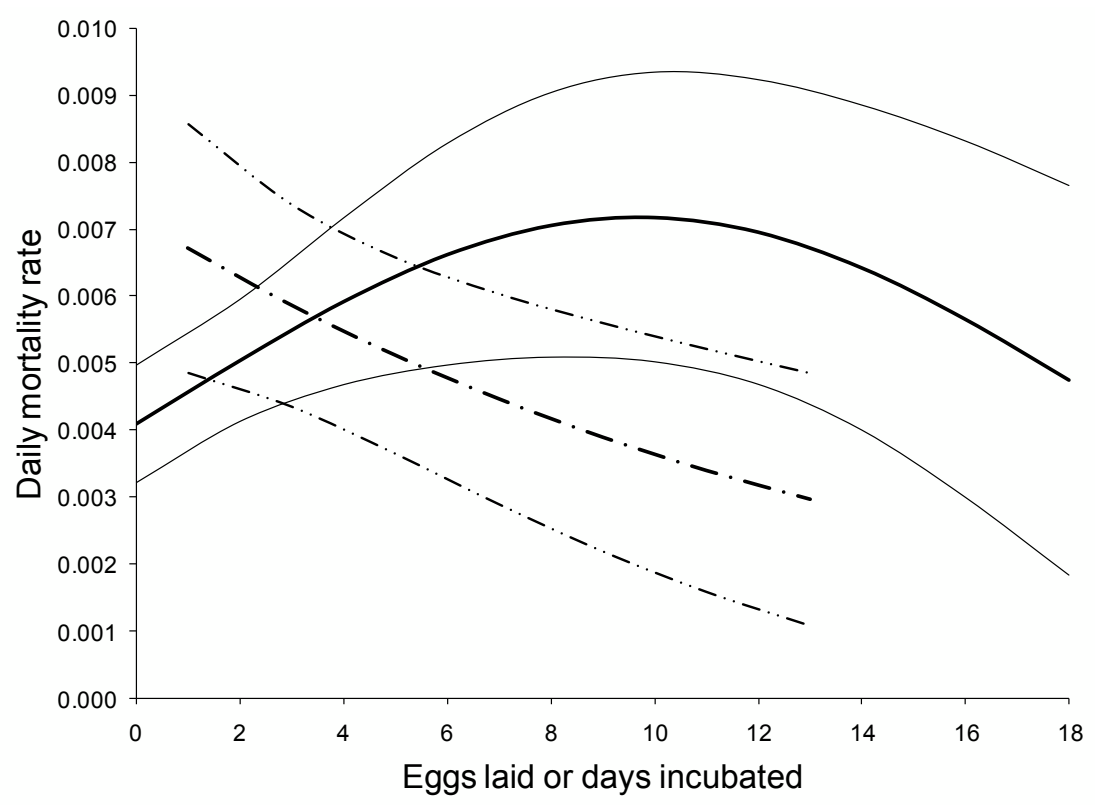


Fig. A1.2. Model-based estimates of daily mortality rate (with $85 \%$ prediction intervals) during the brood-rearing period in relation to brood age (top) and body mass during late incubation (bottom).
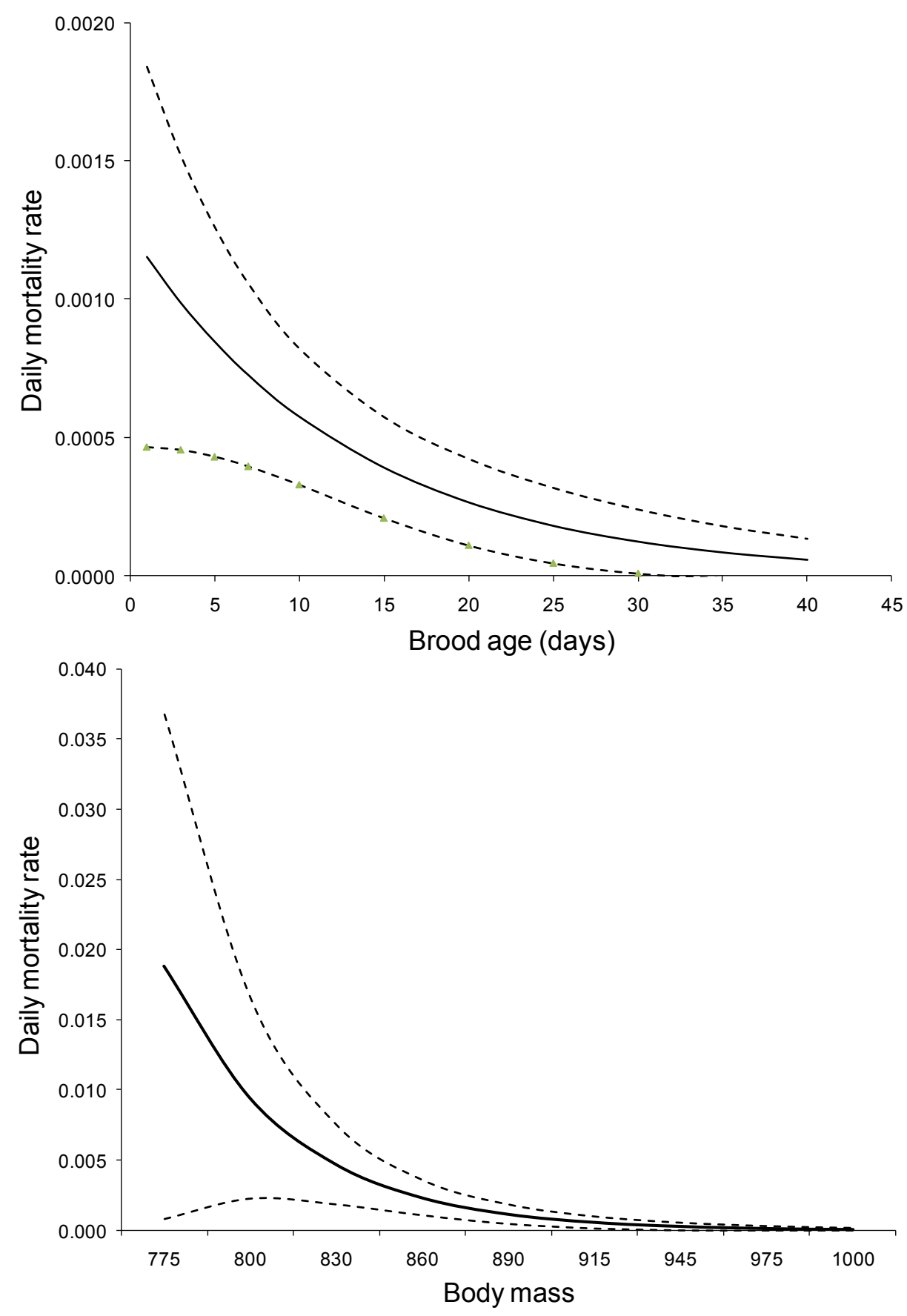
Fig. A1.3. Daily mortality rate (DMR; top pane) and cumulative survival (bottom pane) of four hypothetical female mallards. Mallard 1 (blue line) represents a successful nester: she is marked on 10 April, nests 12 days later (sharp increase in DMR), lays 10 eggs (flat plateau at 0.004 DMR), incubates for 26 days (large hump), hatches a brood (sharp decline) and raises it to fledging age (slow decline in DMR). Mallard 2 (red line) represents a persistent but unsuccessful renester and illustrates the impacts of high cumulative egg production (45 total eggs laid): she begins nesting 5 days after arrival on 10 April, and initiates 6 nests (flat plateaus), all of which fail during the laying stage. After nests 1,3, and 5 fail at the 7-egg stage, she initiates continuation nests and lays 8 more eggs without delay in nests 2, 4, 6, after which she engages in 6-day renesting intervals before resuming again. Although DMR during laying increases after the first clutch of 7 eggs, it declines thereafter, which is inconsistent with the cost of reproduction hypothesis. Despite laying substantially more eggs (45) than Mallards 1 (10) and 3 (19), she has higher cumulative survival because she never incubates. Mallard 3 (green line) represents a bird that engages maximally in incubation: she nests twice and incubates for 25 days before clutch failure (i.e., 50 total days spent incubating). Mortality risk does not go up from cumulative investment, but because she spends 50 total days incubating she has the lowest cumulative mortality of all 4 females. Finally, Mallard 4 (purple line) never initiates a nest and her mortality profile reflects only date effects; she has the highest cumulative survival.

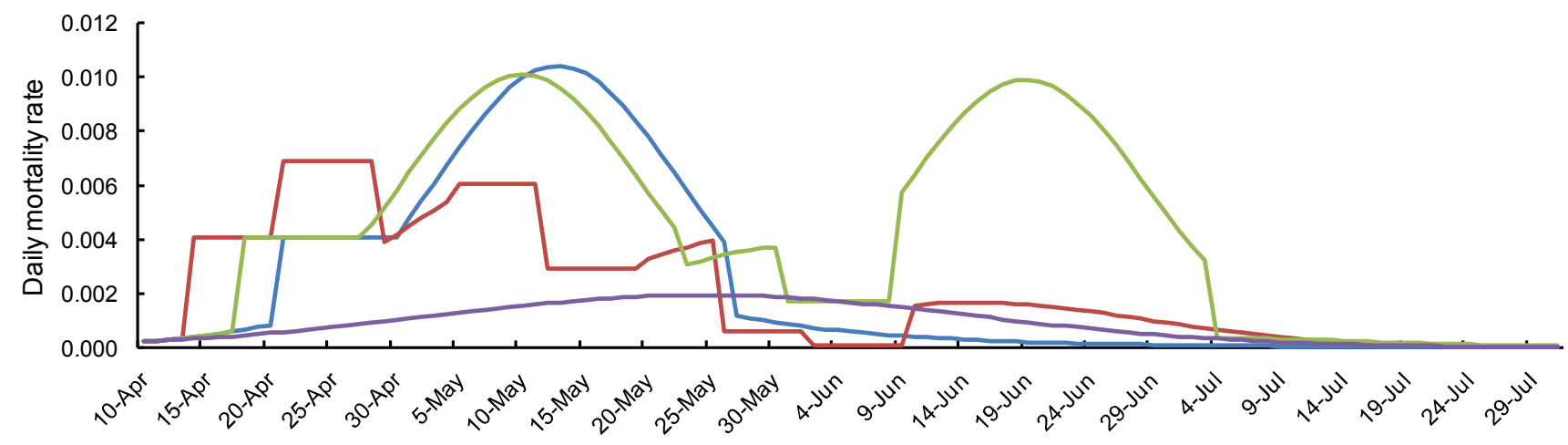




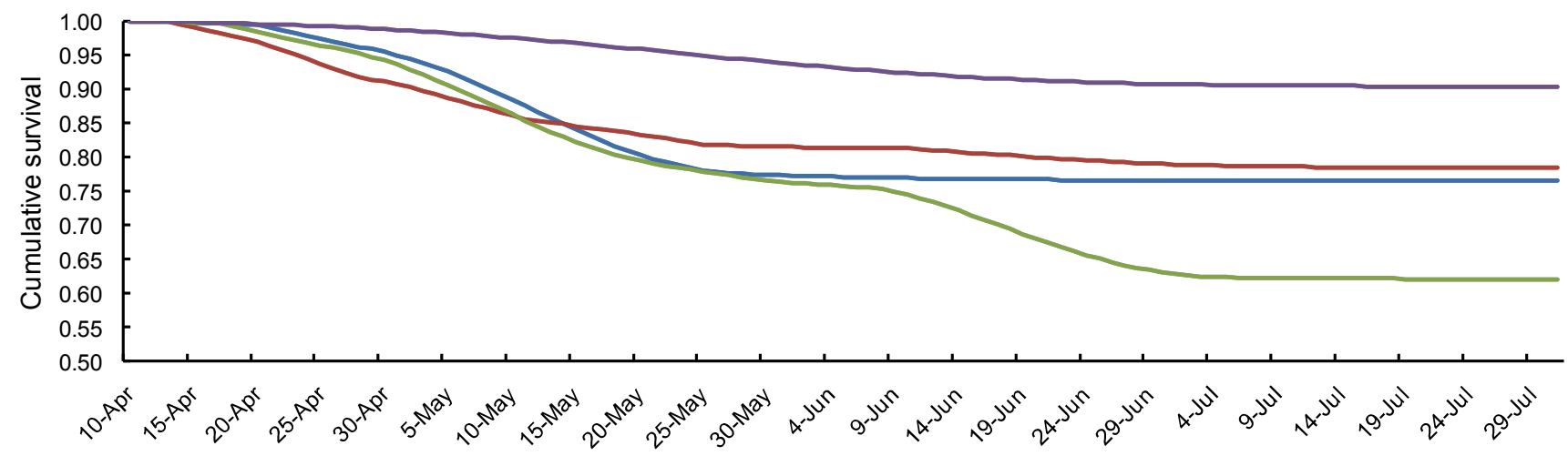

